\title{
The Generation and Trapping of Enantiopure Bromonium Ions $\dagger$
}

\author{
D. Christopher Braddock, ${ }^{* a}$ Stephen A. Hermitage, ${ }^{b}$ Lilian Kwok, ${ }^{a}$ Rebecca Pouwer, ${ }^{a}$ Joanna M. \\ Redmond, ${ }^{a}$ and Andrew J. P. White ${ }^{a}$
}

\author{
Receipt/Acceptance Data [DO NOT ALTER/DELETE THIS TEXT] \\ Publication data [DO NOT ALTER/DELETE THIS TEXT] \\ DOI: 10.1039/b000000x [DO NOT ALTER/DELETE THIS TEXT]
}

Enantiopure bromonium ions may be generated from enantiopure bromohydrins and derivatives. They can be trapped with an in situ nucleophile to give enantiomerically pure products.

The bromonium ion is a species of fundamental interest in organic chemistry. ${ }^{1}$ It was first proposed by Roberts and Kimball in 1937 to account for the well-established stereochemistry of the addition of molecular bromine to olefins. ${ }^{2}$ Milestones in the history of the bromonium ion include Winstein's experiment with 3-bromo-2butanols to prove the existence of a cyclic symmetrical species, ${ }^{3}$ Olah's observation of a bromonium ion by $\mathrm{NMR}^{4}$ and Wynberg's stable bromonium ion of adamantylideneadamantane, ${ }^{5}$ which was subsequently characterised crystallographically and studied by Brown. ${ }^{6,7}$ Herein we report a new milestone: the first generation and trapping of enantiopure bromonium ions to provide enantiomerically pure products.

During the course of our investigations, we observed that the attempted chlorination of ( \pm )-bromophenethylalcohol $\mathbf{1}^{8}$ with thionyl chloride gave $\left( \pm\right.$ )-bromochloride $\mathbf{4}^{9}$ (Scheme 1 ), which was characterised by X-ray crystallography (Figure 1). The position of the chloride was also confirmed by the chlorine-induced isotopic shift method ${ }^{10}$ (see ESI). Evidently, a bromonium ion $3^{\ddagger}$ must form by neighbouring group displacement ${ }^{11}$ of the chlorosulphite group in intermediate $\mathbf{2}$ and is subsequently trapped in Markovnikov manner by chloride as a nucleophile. Since NGP of a bromide will proceed with inversion of stereochemistry at an adjoining stereocentre, and since ring-opening of the resulting cyclic bromonium ion is also expected to be stereospecific, this observation forms the basis for the successful formation and



1

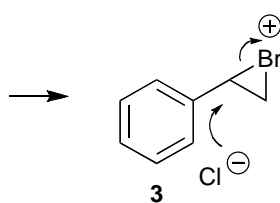

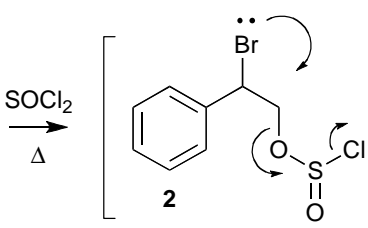

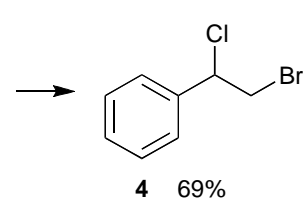

† Electronic Supplementary Information (ESI) available: Full experimental details and characterising data for compounds $\mathbf{4}$ and $\mathbf{6 - 2 4}$, copies of ${ }^{1} \mathrm{H}$ and ${ }^{13} \mathrm{C}$ NMR spectra for 13-22, copies of ${ }^{1} \mathrm{H}$ NMR spectra of Mosher ester derivatives of $\mathbf{6 , 7 , 9 , 1 0 , 2 3}$ and 24, chiral HPLC analysis of 11\&12, optical rotation measurements and ee calculations for 13 and 14, copies of ${ }^{13} \mathrm{C}$ NMR spectra showing halide-induced isotopic shifts for 4, 13, 14, 23 and 24, and X-ray crystallographic details for 4 and 11.

http://www.rsc.org/suppdata/xx/b0/b000000x/

* c.braddock@imperial.ac.uk trapping of enantiopure bromonium ions (vide infra).

Scheme 1. Reaction of alcohol 1 with thionyl chloride.

Figure 1. The molecular structure of $\mathbf{4 - A}$, the major occupancy molecule present in the crystals of bromo-chloride 4 .

Accordingly, we expected to be able to form enantiopure bromonium ions from enantiopure bromohydrins. Commercially available (1S,2S)-1-phenylpropylene oxide (5) was treated with $48 \% \mathrm{HBr}^{12}$ to give an inseparable 3:1 ratio of enantiopure diastereoisomers $1 R, 2 S-6$ and $1 S, 2 S-7$ (Scheme 2). ${ }^{\S}, 13$ The minor diastereoisomer 7 must arise from the partial intervention of a benzylic cation. ${ }^{14}$ However, the stereocentre at the homobenzylic position ensures that they retain their overall enantiomeric integrity. Alternatively, application of Jacobsen's highly efficient kinetic resolution procedure ${ }^{15}$ gave terminal $2 R$-epoxide $\mathbf{8}^{16}$ as essentially a single enantiomer ( $>98 \%$ ee) from racemic dodecane oxide. This was treated with $\mathrm{HBr}$ also, to give separable enantiopure bromohydrins $2 S-9$ and $2 R-10.17$ We now sought to transform these bromohydrins into their enantiopure bromochlorides 11-14 via the intermediacy of enantiopure bromonium ions $\mathbf{A}$ and $\mathbf{B}$. We elected to use neat thionyl chloride as an in situ activator, as above. $^{18}$ Additionally, we prepared tosylates 15-18, and Lepore's sulphonates $^{19}$ 19-22. We intended to activate these sulphonate substrates by the addition of titanium tetrachloride. ${ }^{20}$ To generate authentic bromochlorides $\mathbf{1 3}$ and $\mathbf{1 4}$ of known configuration and regiochemistry, epoxide $\mathbf{8}$ was ring-opened with hydrochloric acid to give a mixture of separable enantiopure chlorohydrins (S)-23 and (R)-24. ${ }^{\S, 21}$ Their regiochemistries were unambiguously identified on the basis of the chlorine isotopic shift method ${ }^{10}$ (see ESI). Appel bromination ${ }^{22}$ of each alcohol gave the individual enantiopure bromochlorides $S-\mathbf{1 3}\left([\alpha]_{\mathrm{D}}-29\right)$ and $S-\mathbf{1 4}\left([\alpha]_{\mathrm{D}}-32\right)$. A combination of DEPT NMR spectroscopy and the halide-induced 
isotopic shift method ${ }^{10}$ unambiguously confirmed their identities (see ESI).

$$
\begin{aligned}
& \text { Reagents and Conditions: } \\
& \text { (i) TsCl, DMAP, } \mathrm{CH}_{2} \mathrm{Cl}_{2} \\
& \text { (ii) } \mathrm{Bs}^{*} \mathrm{Cl}, \mathrm{DMAP}, \mathrm{CH}_{2} \mathrm{Cl}_{2}
\end{aligned}
$$

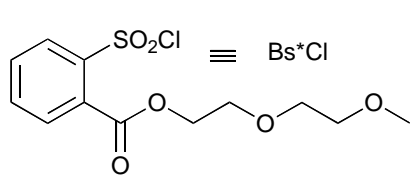<smiles>CC(Br)C(Cl)c1ccccc1</smiles><smiles>[14CH3]</smiles>
12<smiles>[R6]C(C)C(Br)c1ccccc1</smiles>

(i), $94 \% \longrightarrow$ 15: $R=T s$ (ii), $72 \% \underset{\text { 6: }}{\longrightarrow} \mathrm{R}=\mathrm{H}$ 5 $\underset{\substack{\mathrm{CHCl}_{3},-10 \mathrm{C} \\ 88 \%}}{\stackrel{\mathrm{HBr}}{\longrightarrow}}$

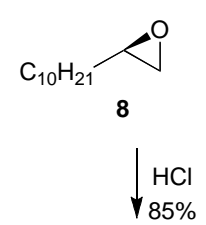

$$
\underset{84 \%}{\stackrel{\mathrm{HBr}}{\longrightarrow}}
$$$$
\mathrm{C}_{10} \overbrace{\mathrm{H}_{21}}^{\mathrm{Br}} \overbrace{\mathrm{C}_{10} \mathrm{H}_{21}}^{+} \overbrace{\mathrm{Br}}^{\mathrm{OR}}
$$

\section{(i), $79 \% \square$ 17: $\mathrm{R}=\mathrm{Ts}$}

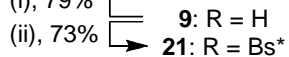

18: $\mathrm{R}=\mathrm{Ts} \hookrightarrow$ (i), $87 \%$

10: $\mathrm{R}=\mathrm{H} \Longrightarrow$ (i), $87 \%$<smiles>CCCCC(Cl)CO</smiles>

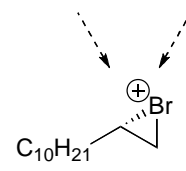

B

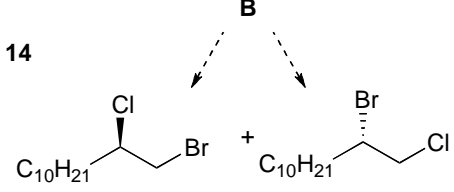

13
Scheme 2. Preparation of substrates and expected products via enantiopure bromonium ions $\mathbf{A}$ and $\mathbf{B}$.

The diastereomeric mixture of enantiopure aryl bromohydrins 6 and 7 were treated with neat thionyl chloride at $65^{\circ} \mathrm{C}$ (Table 1 , entry 1$)$. In the event, the reaction proceeded smoothly to give enantiomerically pure bromochlorides $1 S, 2 R-11$ and $1 R, 2 R-12$ as a 3:1 mixture in excellent yield. ${ }^{\dagger+, 23}$ Evidently, each diastereoisomer has proceeded through the enantiomerically pure bromonium ion $\mathbf{A}^{\ddagger}$ as expected with a signature inversion of stereochemistry at the 2-position. Subsequent Markovnikov trapping of the bromonium ion has occurred to give the two possible benzylic chloride diastereomers.** To the best of our knowledge this constitutes the first time that an enantiopure bromonium ion $^{\ddagger}$ has been generated and trapped to give enantiopure products. The mixture of tosylates (entry 2) and modified benzenzenesulphonates (entry 3) proved to be activated on treatment with titanium tetrachloride to give the bromochloride products in excellent yields, with complete enantiospecificity. $^{\dagger+}$ Evidently, these proceed via enantiopure bromonium ion $\mathbf{A}$ also. ${ }^{\ddagger}$ Interestingly, using these sulphonates, the
NGP of the resident bromine on the Lewis acid-activated leaving group must be faster than any possible competing $\mathrm{S}_{\mathrm{N}} \mathrm{i}$ process. ${ }^{20}$

Table 1 Bromochlorides via enantiomerically pure bromonium ions ${ }^{a}$

\begin{tabular}{cccccc}
\hline Entry & Substrate & Reagent & Product & \%yield & \%ee \\
1 & $\mathbf{6 \& 7}(73: 23)$ & $\mathrm{SOCl}_{2}$ & $\mathbf{1 1 \& 1 2}(76: 24)$ & 97 & $>98^{c}$ \\
2 & $\mathbf{1 5 \& 1 6}(70: 30)$ & $\mathrm{TiCl}_{4}$ & $\mathbf{1 1 \& 1 2}(67: 33)$ & 100 & $>98^{c}$ \\
3 & $\mathbf{1 9 \& 2 0}(65: 35)$ & $\mathrm{TiCl}_{4}$ & $\mathbf{1 1 \& 1 2}(86: 14)$ & 89 & $>98^{c}$ \\
4 & $\mathbf{9}$ & $\mathrm{SOCl}_{2}$ & $\mathbf{1 3 \& 1 4}(58: 42)$ & 57 & $77 \pm 5^{d}$ \\
5 & $\mathbf{1 0}$ & $\mathrm{SOCl}_{2}$ & $\mathbf{1 3 \& 1 4}(58: 42)$ & 53 & $68 \pm 5^{d}$ \\
6 & $\mathbf{1 7}$ & $\mathrm{TiCl}_{4}$ & $\mathbf{1 3 \& 1 4}(87: 13)$ & 95 & $100 \pm 5^{d}$ \\
7 & $\mathbf{1 8}$ & $\mathrm{TiCl}_{4}$ & $\mathbf{1 3 \& 1 4}(86: 14)$ & 87 & $103 \pm 5^{d}$ \\
8 & $\mathbf{2 1}$ & $\mathrm{TiCl}_{4}$ & $\mathbf{1 3 \& 1 4}(76: 24)$ & 92 & $104 \pm 5^{d}$ \\
9 & $\mathbf{2 2}$ & $\mathrm{TiCl}_{4}$ & $\mathbf{1 3 \& 1 4}(71: 29)$ & 95 & $103 \pm 5^{d}$
\end{tabular}

${ }^{a}$ See ESI for experimental conditions ${ }^{b}$ After column chromatography. ${ }^{c}$ Determined by chiral HPLC. ${ }^{\dagger \dagger}{ }^{d}$ Determined by optical rotation. ${ }^{\text {qf }}$

Experiments using the separable alkyl bromohydrins $\mathbf{9}$ and $\mathbf{1 0}$, and their sulphonate derivatives (entries 4-9) give unambiguous evidence for the formation of alkyl bromonium ion B. Firstly, when treated with thionyl chloride each of $\mathbf{9}$ and $\mathbf{1 0}$ gave the same product distribution of (inseparable) bromochlorides 13 and 14 implicating formation of a common intermediate, to wit, the bromonium ion B. Constant product distributions - within experimental error - were also observed in the cases of regioisomeric tosylates (entries 6 and 7) and benzenesulphonates (entries 8 and 9) showing that these also proceed through bromonium ion $\mathbf{B}$. The difference in product distributions between the bromohydrin and sulphonate substrates can be largely attributed to the operating temperature $\left(65^{\circ} \mathrm{C}\right.$ versus $-78^{\circ} \mathrm{C}$ respectively). The difference in product distributions between the tosylate and benzenesulphonate substrates should reflect a change in ion-pairing of the nascent bromonium ion $\mathbf{B}$ and the incoming chloride nucleophile as modified by the leaving Lewis acid-bound sulphonate.

Secondly, analysis of the enantiomeric composition of the various product mixtures of $\mathbf{1 3}$ and $\mathbf{1 4}$ proves to be entirely consistent with formation of enantiomerically pure bromonium ion B. Since NGP by a bromide will proceed with inversion at any adjoining stereocentre then each substrate $\mathbf{9 , 1 0 , 1 7 , 1 8 , 2 1}$ or 22 can only produce the $S$-configured bromonium ion $\mathbf{B}$. Attack of the chloride nucleophile at the Markovnikov position will result in inversion and a $R$-configured chloride 13 , whereas attack at the terminal position will leave the bromide $\mathbf{1 4}$ as $S$-configured. For the sulphonate substrates 17, 18, 21 or 22 as activated by titanium tetrachloride (Table 1, entries 6-9), the bromochlorides 13 and $\mathbf{1 4}$ are produced with essentially complete enantiospecificity. ${ }^{\text {IT }}$ Thus, the mapping of the stereochemical course of the reaction provides irrefutable evidence for the intermediacy of enantiopure bromonium ion B. Interestingly, when thionyl chloride was used (Table 1, entries 4 and 5) the bromochlorides $\mathbf{1 3}$ and $\mathbf{1 4}$ are formed with reduced enantiomeric purity. From the work of Brown, ${ }^{23}$ it seems reasonable to suggest a competing pathway for formation of $\mathrm{BrCl}$ by direct attack of free chloride in solution on the bromonium ion. Re-addition of $\mathrm{BrCl}$ to the resulting olefin occurs without control of absolute stereochemistry and some leakage of enantiomeric purity occurs.

In conclusion, we have shown that enantiopure bromohydrins can be used to generate enantiopure bromonium ions. These may be trapped with a nucleophile to provide enantiomerically pure 
bromine containing products. Since the bromonium ion precursors are generated from readily available enantiopure epoxides, these results open the door for the use of enantiopure bromonium ions in asymmetric synthesis. We regard this as a significant advance in the use of bromonium ions in synthetic organic chemistry.

We thank the EPSRC and GlaxoSmithKline for a Industrial CASE award (to J. M. R.), and the EPSRC for further financial support (EPSRC Grant no. EP/E058272/1).

D. Christopher Braddock, ${ }^{* a}$ Stephen A. Hermitage, ${ }^{b}$ Lilian Kwok, ${ }^{a}$ Rebecca Pouwer, ${ }^{a}$ Joanna M. Redmond, ${ }^{b}$ and Andrew J. P. White ${ }^{a}$

${ }^{a}$ Department of Chemistry, Imperial College London, London, SW7 2AZ, UK. Fax: +44(0)2075945805; Tel: +44(0)2075945772; E-mail: c.braddock@imperial.ac.uk.

${ }^{b}$ GlaxoSmithKline Ltd, Medicines Research Centre, Gunnels Wood Road, Stevenage SG1 2NY, UK

\section{Notes and references}

‡ The exact structure of a "bromonium ion" of a styrene depends strongly on any substituents and on the solvent, and it is understood that a spectrum of ionic intermediates are possible, of which the cyclic bromonium ion and the open $\beta$-bromocarbocation are the extremes. See references $1 \mathrm{a}$ and $1 \mathrm{~b}$.

$\S$ The enantiomeric purity was assayed by Mosher ester formation and comparision with the Mosher ester of the racemic halohydrin prepared in identical fashion from racemic epoxide (see ESI).

${ }^{+t}$ The enantiomeric purity was assayed by chiral HPLC methods by reference to a racemic sample (see ESI)

** A racemic sample of the major diastereomer $\mathbf{1 1}$ proved to be crystalline and the relative stereochemistry was confirmed by X-ray crystallography. Both diastereoisomers showed characteristic benzyl chloride fragments in their MS allowing the minor diastereoisomer to be assigned as 12 (see ESI).

ๆT The \%ee was calculated on the basis of known specific rotations for enantiomerically pure $S-13\left([\alpha]_{D}-29\right)$ and $S-14\left([\alpha]_{D}-32\right)$. Since a mixture of $R-13$ and $S-14$ are obtained, the \%ee can be calculated by [optical rotation of mixture/(0.01*((\%13*29)+(\%14*-32)))] (see ESI).

1 (a) Yates, K.; McDonald, R. S. J. Org. Chem. 1973, 38, 7, 24652478; (b) Ruasse, M.-F. Acc. Chem. Res. 1990, 23, 87-93.

2 Roberts, I.; Kimball, G. E. J. Am. Chem. Soc. 1937, 59, 947-948.

3 Winstein, S.; Lucas, H. J. J. Am. Chem. Soc. 1939, 61, 2845-2848.

4 (a) Olah, G. A.; Bollinger, J. M.; Brinich, J. J. Am. Chem. Soc. 1968, 90, 2587-2594; (b) Olah, G.A.; Bollinger, J. M. J. Am. Chem. Soc. 1968, 90, 6082-6086.

5 Strating, J.; Wieringa, J. H.; Wynberg, H. J. Chem. Soc., Chem. Commun. 1969, 907-908.

6 (a) Slebocka-Tilk, H.; Ball, R. G.; Brown, R. S. J. Am. Chem. Soc. 1985, 107, 4504-4508; (b) Bennet, A. J.; Brown, R. S.; McClung, R. E. D.; Klobukowski, M.; Aarts, G. H. M.; Santarsiero, B. D.; Bellucci, G.; Bianchini, R. J. Am. Chem. Soc. 1991, 113, 8532-8535; (c) Brown, R. S.; Nagorski, R. W.; Bennet, A. J.; McClung, R. E. D.; Aarts, G. H. M.; Klobukowski, M.; McDonald, R.; Santarsiero, B. D. J. Am. Chem. Soc. 1994, 116, 2448-2456.

7 Brown, R. S. Acc. Chem. Res. 1997, 30, 131-137, and references cited therein.

8 Buckles, R. E.; Maurer, J. E. J. Org. Chem. 1953, 18, 1585-1590.

9 Buckles, R. E.; Long, J. W. J. Am. Chem. Soc. 1951, 73, 998-1000.

10 (a) For chlorine: Sergeyev, N. M.; Sergeyeva, N. D.; Raynes, W. T. J. Magn. Res., Ser. A 1995, 115, 174-182. (b) For bromine: Raynes, W. T.; Sergeyev, N. M.; Sandor, P.; Grayson, M. Mag. Res. Chem. 1997, 35, 141-143.

11 For the NGP participation of bromine in 2-cyclohexyl benzenesulphonates see: Grunwald, E. J. Am. Chem. Soc. 1951, 73, 5458-5459.

12 Sharghi, H.; Eskandari, M. M. Synthesis 2002, 1519-1522.

13 The racemic compounds are both known: Soladié-Cavallo, A.; Lupattelli, P.; Bonini, C. J. Org. Chem. 2005, 70, 1605-1611.
14 Ruasse, M.-F.; Lo Moro, G.; Galland, B.; Bianchini, R.; Chiappe, C.; Bellucci, G. J. Am. Chem. Soc. 1997, 119, 12492-12502, and references cited therein.

15 Schaus, S. E.; Brandes, B. D.; Larrow, J. F.; Tokunaga, M.; Hansen, K. B.; Gould, A. E.; Furrow, M. E.; Jacobsen, E. N. J. Am. Chem. Soc. 2002, 124, 1307-1315.

16 Savle, P. S.; Lamoreaux, M. J.; Berry, J. F.; Gandour, R. D. Tetrahedron: Asymm. 1998, 9, 1843-1846.

17 The racemic compounds are both known: Cerichelli, G.; Grande, C.; Luchetti, L.; Mancini, G. J. Org. Chem. 1991, 56, 3025-3030.

18 A bromohydrin of unspecified stereochemistry has been converted into a bromochloride of unspecified stereochemistry using Viehe's salt in a synthesis of halomon, where a bromonium ion was implicated to account for bromine migration: Schlama, T.; Baati, R.; Gouverneur, V.; Valleix, Falck, J. R.; Mioskowski, C. Angew. Chem. Int. Ed. 1998, 37, 2085-2087.

19 Lepore, S. D.; Bhunia, A. K.; Cohn, P. J. Org. Chem. 2005, 70, $8117-$ 8121.

20 The treatment of a Lepore sulphonate with titanium tetrachloride has been reported to give the alkyl chloride with retention of configuration: Lepore, S. D.; Bhunia, A. K.; Mondal, D.; Cohn, P. C.; Lefkowitz, C. J. Org. Chem. 2006, 71, 3285-3286.

21 The racemic compounds are both known: Garrett, C. E.; Fu, G. C. J. Org. Chem. 1997, 62, 4534-4535.

22 Appel, R. Angew. Chem., Int. Ed. Engl. 1975, 14, 801-811.

23 The racemic compounds are both known: Heasley, G.; Bundy, J. M.; Heasley, V. L.; Arnold, S.; Gipe, A.; McKee, D.; Orr, R.; Rodgers, S. L.; Shellhamer, D. F. J. Org. Chem. 1978, 43, 2793-2799.

24 Zheng, C. Y.; Slebocka-Tilk, H.; Nagorski, R. W.; Alvarado, L.; Brown, R. S. J. Org. Chem. 1993, 58, 2122-2127 and references cited therein. 


\section{Graphical Abstract}

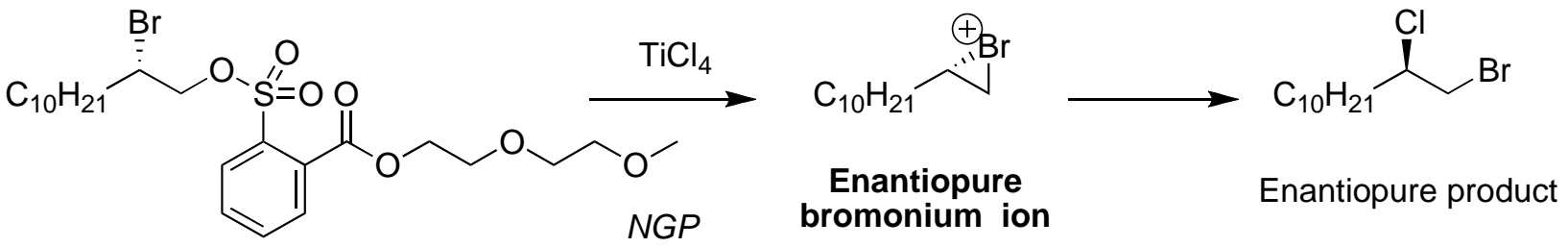

Enantiopure bromhydrin derivative 